\title{
Clustering of Rainfall Distribution Patterns in Peninsular Malaysia using Time Series Clustering Method
}

\author{
Noratiqah Mohd Ariff ${ }^{1 a}$, Mohd Aftar Abu Bakar ${ }^{1 b *}$, Sharifah Faridah Syed Mahbar ${ }^{2 c}$, Mohd \\ Shahrul Mohd Nadzir ${ }^{3,4 d}$
}

${ }^{1}$ School of Mathematical Sciences, Faculty of Science and Technology, Universiti Kebangsaan Malaysia, 43600 UKM Bangi, Selangor, MALAYSIA. E-mail: tqah@ukm.edu.my ${ }^{a}$; aftar@ukm.edu.my ${ }^{b}$

${ }^{2}$ Pusat Operasi Cuaca \& Geofizik Nasional, Jabatan Meteorologi Malaysia, Kementerian Tenaga, Sains, Teknologi, Alam Sekitar \& Perubahan Iklim, Jalan Sultan, 46667 Petaling Jaya, Selangor, MALAYSIA. E-mail: aridah_mahbar@met.gov.my ${ }^{\mathrm{c}}$

${ }^{3}$ School of Environmental and Natural Resource Sciences, Faculty of Science and Technology, Universiti Kebangsaan Malaysia, 43600, UKM Bangi, Selangor, MALAYSIA.

${ }^{4}$ Centre for Tropical Climate Change System, Institute of Climate Change, Universiti Kebangsaan Malaysia, 43600, UKM Bangi, Selangor, MALAYSIA. E-mail: shahrulnadzir@ukm.edu.my ${ }^{\mathrm{d}}$

* Corresponding Author: aftar@ukm.edu.my ${ }^{\mathrm{b}}$

Received: $21^{\text {st }}$ April $2019 \quad$ Revised: $6^{\text {th }}$ August $2019 \quad$ Published: $30^{\text {th }} \quad$ September 2019

DOI : https://doi.org/10.22452/mjs.sp2019no2.8

\begin{abstract}
Time series clustering technique was used in this study to categorize the locations in Peninsular Malaysia according to the similarity of rainfall distribution patterns. Daily rainfall time series data from 12 meteorological observation stations across Peninsular Malaysia have been considered for this study. Four dissimilarity measure methods were examined and compared in terms of accuracy and suitability, namely Euclidean distance (ED), complexityinvariant distance (CID), correlation-based distance (COR) and integrated periodogram-based distance (IP). The average silhouette width (ASW) was used to determine the optimal group number for the rainfall time series data. Using Ward's hierarchical clustering method, this study found that the rainfall time series in Peninsular Malaysia can be divided into four regions of homogeneous climate zones. Based on the results, the IP was the most suitable dissimilarity measures for clustering rainfall time series data in Peninsular Malaysia, except during the Southwest Monsoon where the COR performed better.
\end{abstract}

Keywords: time series clustering, dissimilarity measures, rainfall patterns, Peninsular Malaysia.

\section{INTRODUCTION}

Accuracy in weather forecasting helps to contribute to the nation socioeconomic activities and development. The weather reports are used in planning and decision making for matters related to disaster management, water management, agriculture, industry and tourism. Clustering technique is one of the effective data mining techniques to extract useful information. It is important to identify the set of objects whose class is unknown in data mining. This has been applied in the study of taxonomy, agriculture, remote sensing and process control (Kavitha \& Punithavalli, 2010), as well as meteorology study to determine and classify rainfall patterns (Munoz-Diaz \& Rodrigo, 2004; Soltani \& Modarres, 2006).

Time series clustering is a technique which can partition time series data into groups based on its similarity or distance. Time series clustering has been used for recognizing dynamic changes in time series, discovering patterns, prediction and 
THE INTERNATIONAL SEMINAR ON MATHEMATICS IN INDUSTRY (ISMI) AND THE INTERNATIONAL CONFERENCE ON THEORETICAL AND APPLIED STATISTICS (ICTAS) ISMI-ICTAS18 [4-6 SEPTEMBER 2018]

recommendation in many field of studies such as in climate, energy, environment, finance and medicine (Aghabozorgi et al., 2015; Rani $\&$ Sikka, 2012). Ahmad et al. (2013) used the hierarchical clustering approach to regionalise the daily rainfall data in Peninsular Malaysia. However, they do not consider the seasonal factor, which is crucial for the Malaysian climate. This was conducted by clustering the time series data only during the Northeast Monsoon (or Southwest Monsoon), instead of clustering the whole time series.

In this study, the rainfall time series data from 12 meteorological stations in Peninsular Malaysia from 1970 to 2014 (45 years) were analysed using clustering technique. This study examined and compared four dissimilarity measure methods used to cluster the rainfall time series in Malaysia according to homogenous climate zone.

\section{RAINFALL DATA}

Malaysia is a country located near to the equator, divided into two regions which are the Peninsular Malaysia and East Malaysia separated by the South China Sea. The climate is hot and humid throughout the year with heavy rainfalls. There are two monsoon seasons, the Southwest Monsoon (May to August), where the east coast of Peninsular Malaysia, west of Sarawak and east coast of Sabah have more rainfalls, and the Northeast Monsoon (November to February), where the rainfall occurrence is lesser at the east coast of Peninsular Malaysia. The total precipitation is between 2000 and $4000 \mathrm{~mm}$ annually.

Twelve Malaysian Meteorological Department (MMD) observation stations that cover three zones in Peninsular Malaysia were selected in this study. Details for each station and its location is depicted in Table 1 and Figure 1. The daily time series rainfall data from 1970 until 2014 were used in this analysis.

Table 1: Stations details, location and percentage of missing data for each station.

\begin{tabular}{lccccc}
\hline \multicolumn{1}{c}{ Station } & $\begin{array}{c}\text { Station } \\
\text { Code }\end{array}$ & $\begin{array}{c}\text { Latitude } \\
\left({ }^{\circ} \mathbf{N}\right)\end{array}$ & $\begin{array}{c}\text { Longitude } \\
\left({ }^{\circ} \mathbf{E}\right)\end{array}$ & $\begin{array}{c}\text { Mean Sea } \\
\text { Level } \\
(\mathbf{M S L}) \\
(\mathbf{m})\end{array}$ & $\begin{array}{c}\text { Missing } \\
\text { Data } \\
(\boldsymbol{\%})\end{array}$ \\
\hline Alor Setar & 48603 & 6.2 & 100.4 & 3.9 & - \\
Bayan Lepas & 48601 & 5.3 & 100.2667 & 2.5 & - \\
Kota Bharu & 48615 & 6.1667 & 102.3 & 4.4 & - \\
Hospital Dungun & 49476 & 4.7667 & 103.4167 & 3 & 2.46 \\
Kuantan & 48657 & 3.7667 & 103.2167 & 15.2 & - \\
Mersing & 48674 & 2.45 & 103.8333 & 43.6 & - \\
Subang & 48647 & 3.1333 & 101.55 & 16.6 & - \\
Malacca & 48665 & 2.2667 & 102.25 & 8.5 & - \\
Hospital Baling & 41545 & 5.6833 & 100.9167 & 52 & 0.42 \\
Ipoh & 48625 & 4.5667 & 101.1 & 40.1 & - \\
Hospital Tapah & 43421 & 4.2 & 101.2667 & 35 & 0.27 \\
Sitiawan & 48620 & 4.2167 & 100.7 & 6.8 & - \\
\hline
\end{tabular}


THE INTERNATIONAL SEMINAR ON MATHEMATICS IN INDUSTRY (ISMI) AND THE INTERNATIONAL CONFERENCE ON THEORETICAL AND APPLIED STATISTICS (ICTAS) ISMI-ICTAS18 [4-6 SEPTEMBER 2018]

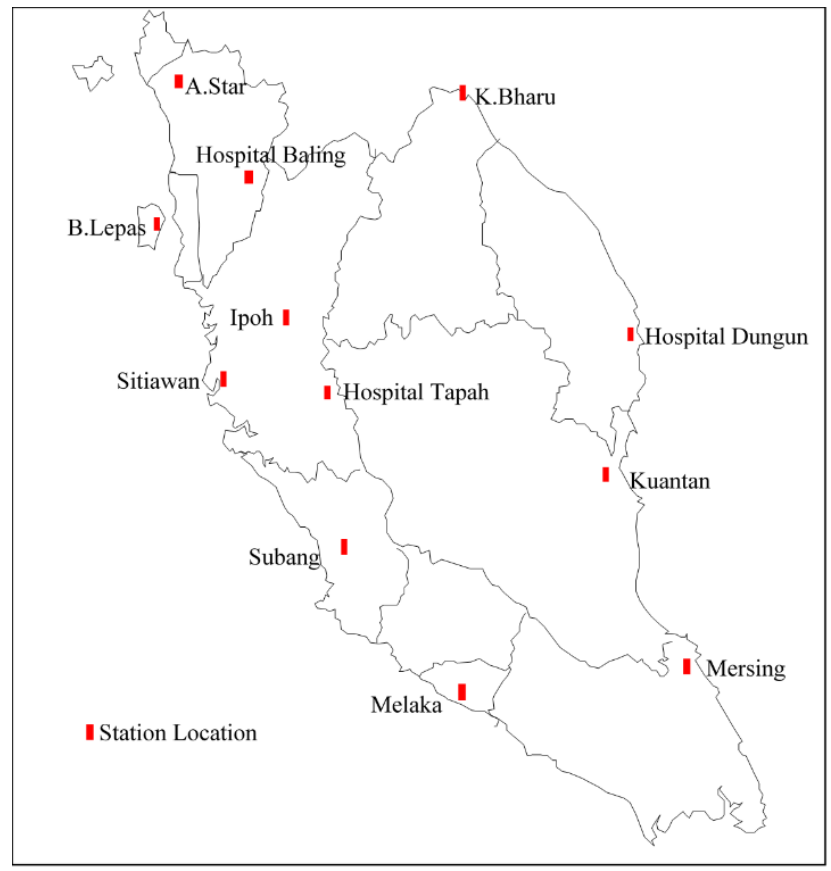

Figure 1: Locations of rain gauge stations.

\section{TIME SERIES CLUSTER} ANALYSIS

Cluster analysis is a technique that groups certain observations with similar characteristics or traits when the true group is unknown. Cluster analysis is applied in various data types, for example numerical data (Michinaka et al., 2011), image data (Arifin \& Asano, 2006) and text data (Ariff et al., 2018). Time series clustering have been used in many areas of hydrology, such as to determine and group stations according to its homogeneous climate areas (DeGaetano,2001) or time frame according to a cluster that represents weather events or patterns (Ramos, 2001).

Generally, there are three types of time series, which are whole time series clustering, sub-sequence time-series clustering and timepoint clustering (Aghabozorgi et al., 2015). For this study, only whole time series clustering will be considered since the purpose is to compare several meteorological observation stations rainfall time series data with respect to their similarity. Han et al.
(2012) have classified clustering methods into five categories:

- partitioning method

- hierarchical method

- probabilistic model-based method

- density-based method

- grid-based method

The first three methods were used directly or modified for time series clustering. Partition clustering aims to separate set of objects into consistent group. At first, the objects will be placed randomly and later transferred into another cluster until being positioned in an almost similar group while for hierarchical clustering, each object is defined as a single group. Then, each object (group) will be merged to form a new one. The merging process continues until only one group is left.

In this study, Ward's hierarchical clustering was used to cluster the rainfall time series data in Peninsular Malaysia. Several studies have shown that Ward's approach is suitable for clustering the rainfall data since the clusters do not have to be equiprobable 
THE INTERNATIONAL SEMINAR ON MATHEMATICS IN INDUSTRY (ISMI) AND THE INTERNATIONAL CONFERENCE ON THEORETICAL AND APPLIED STATISTICS (ICTAS) ISMI-ICTAS18 [4-6 SEPTEMBER 2018]

which imply that the number of stations in each cluster does not have to be equal. (Ramos, 2001; Tennant \& Hewitson, 2002; Crétat et al., 2012).

The use of Ward's method in hierarchical clustering is to minimise the loss of information resulted from the combination of clusters. At each stage, the combination of each pair of possible clusters is considered and the combination of two clusters will increase the sum of squared errors (SSE). Eventually, all clusters will be combined into one large cluster with larger SSE value.

\subsection{Dissimilarity Measures}

The most important step prior to algorithm clustering is to generate numerical similarity and dissimilarity measures to characterise relationships between data (Munoz-Diaz \& Rodrigo, 2004; Prasanna, 2012). According to Lin \& Li (2009), the similarity or dissimilarity between time series can be based on shape or structure concepts. The dissimilarity shape concept measures the similarity or dissimilarity based on the geometric of the series; this concept was commonly known as model free approachwhile the structure concept, also known as model based approach measure the dissimilarity based on the global underlying structure of the series.

Three model free dissimilarity measures have been selected in this study which are Euclidean distance (ED), correlation-based distance (COR) and integrated periodogram-based distance (IP). The complexity-invariant distance (CID) which is a model-based dissimilarity measure was also considered in this study.

Euclidean distance is the most common and easiest shape based dissimilarity measure for time series data. ED is calculated by

$$
\operatorname{ED}\left(\mathbf{X}_{\mathbf{T}}, \mathbf{Y}_{\mathbf{T}}\right)=\sqrt{\sum_{t=1}^{T}\left(X_{t}-Y_{t}\right)^{2}},
$$

where $\boldsymbol{X}_{T}$ and $\boldsymbol{Y}_{T}$ are two different time series.

Pearson correlation coefficient is selected in this study as the correlation-based dissimilarity measure. Highly correlated

values mean that the distance is close and the formulae Pearson correlation is given as follows;

$$
\operatorname{COR}\left(\mathbf{X}_{\mathbf{T}}, \mathbf{Y}_{\mathbf{T}}\right)=\frac{\sum_{t=1}^{T}\left(X_{t}-\bar{X}_{T}\right)\left(Y_{t}-\bar{Y}_{T}\right)}{\sqrt{\sum_{t=1}^{T-1}\left(X_{T}-\bar{X}_{T}\right)^{2}} \sqrt{\sum_{t=1}^{T-1}\left(Y_{T}-\bar{Y}_{T}\right)^{2}}}
$$

Periodogram method is used to determine the dominant time period and frequency for a time series. This technique is also used to analyse periodic data by transforming the data into frequency waves. De Lucas (2010) discussed the distance measure on cumulative periodogram known as integrated periodogram (IP). IP calculates the distance difference between two time series in terms of cumulative periodogram. The advantage of this method over the basic periodogram is it can determine the entire stochastic processes that occur in the time series sequence. The steps to calculate IP is given as 
THE INTERNATIONAL SEMINAR ON MATHEMATICS IN INDUSTRY (ISMI) AND THE INTERNATIONAL CONFERENCE ON THEORETICAL AND APPLIED STATISTICS (ICTAS) ISMI-ICTAS18 [4-6 SEPTEMBER 2018]

$$
\operatorname{IP}\left(\mathbf{X}_{\mathbf{T}}, \mathbf{Y}_{\mathbf{T}}\right)=\int_{-\pi}^{\pi}\left|F_{X_{T}}(\lambda)-F_{Y_{T}}(\lambda)\right| d \lambda, \quad \lambda \in[-\pi, \pi]
$$

where

$$
\begin{array}{ll}
F_{X_{T}}\left(\lambda_{j}\right)=C_{X_{T}}^{-1} \sum_{i=1}^{j} I_{X_{T}}\left(\lambda_{i}\right), & C_{X_{T}}=\sum_{i} I_{X}\left(\lambda_{i}\right) \\
F_{Y_{T}}\left(\lambda_{j}\right)=C_{Y_{T}}^{-1} \sum_{i=1}^{j} I_{Y_{T}}\left(\lambda_{i}\right), & C_{Y_{T}}=\sum_{i} I_{Y}\left(\lambda_{i}\right) \\
I_{X_{T}}\left(\lambda_{k}\right)=T^{-1}\left|\sum_{t=1}^{T} X_{T} e^{-i \lambda_{k} t}\right|^{2} & \\
I_{Y_{T}}\left(\lambda_{k}\right)=T^{-1}\left|\sum_{t=1}^{T} Y_{T} e^{-i \lambda_{k} t}\right|^{2} & n=\left[\frac{T-1}{2}\right] \\
\lambda_{k}=\frac{2 \pi k}{T}, & k=1, \ldots, n,
\end{array}
$$

with

$$
\begin{aligned}
T & =\text { vector length, } T \geq 1 \\
I_{X_{T}}\left(\lambda_{k}\right) & =\text { periodogram for } \mathbf{X}_{\mathbf{T}} \\
I_{Y_{T}}\left(\lambda_{k}\right) & =\text { periodogram for } \mathbf{Y}_{\mathbf{T}} .
\end{aligned}
$$

Batista et al. (2014) introduced the CID time series measure, which improves the classification and clustering accuracy without compromising the efficiency. CID measures the complexity difference between two time series. It is a ratio of complexity of one time series to another (the less complex one). Complexity correction factor $(\mathrm{CF})$ will be closer to one if both series have similar complexity level or greater than one if the complexity level of both series is different. CID is calculated by

$$
\operatorname{CID}\left(\mathbf{X}_{\mathrm{T}}, \mathbf{Y}_{\mathrm{T}}\right)=\operatorname{ED}\left(\mathbf{X}_{\mathrm{T}}, \mathbf{Y}_{\mathbf{T}}\right) \times \mathrm{CF}\left(\mathbf{X}_{\mathrm{T}}, \mathbf{Y}_{\mathrm{T}}\right)
$$

where

$$
\operatorname{CF}\left(\mathbf{X}_{\mathbf{T}}, \mathbf{Y}_{\mathbf{T}}\right)=\frac{\max \left(\mathrm{CE}\left(X_{T}\right), \operatorname{CE}\left(Y_{T}\right)\right)}{\min \left(\operatorname{CE}\left(X_{T}\right), \operatorname{CE}\left(Y_{T}\right)\right)}
$$

and the complexity estimate is

$$
\mathrm{CE}\left(\mathbf{X}_{\mathbf{T}}\right)=\sqrt{\sum_{t=1}^{T-1}\left(X_{t}-X_{t+1}\right)^{2}}
$$


THE INTERNATIONAL SEMINAR ON MATHEMATICS IN INDUSTRY (ISMI) AND THE INTERNATIONAL CONFERENCE ON THEORETICAL AND APPLIED STATISTICS (ICTAS) ISMI-ICTAS18 [4-6 SEPTEMBER 2018]

\subsection{Average Silhouette Width}

The optimal number of clusters, $k$, for a dataset is determined in clusterisation process. Out of several ways to determine the $k$ value in this study, the average silhouette width (ASW) was selected.

At first, the average distance for each subject in similar cluster is calculated. Cluster member with the lowest distance shows that the difference between subjects is minimal and can be clustered together. Then, the average distance for each subject will be compared to the average distance of neighbouring cluster members. The difference in ratio obtained from the member's dissimilarity point in the same cluster to the nearest neighbouring cluster is known as the silhouette value. The overall silhouette value is calculated by looking for the average silhouette of each member. This measure the similarity level of cluster members. The ASW value obtained is used to determine the optimal cluster number, $k$, of a dataset.

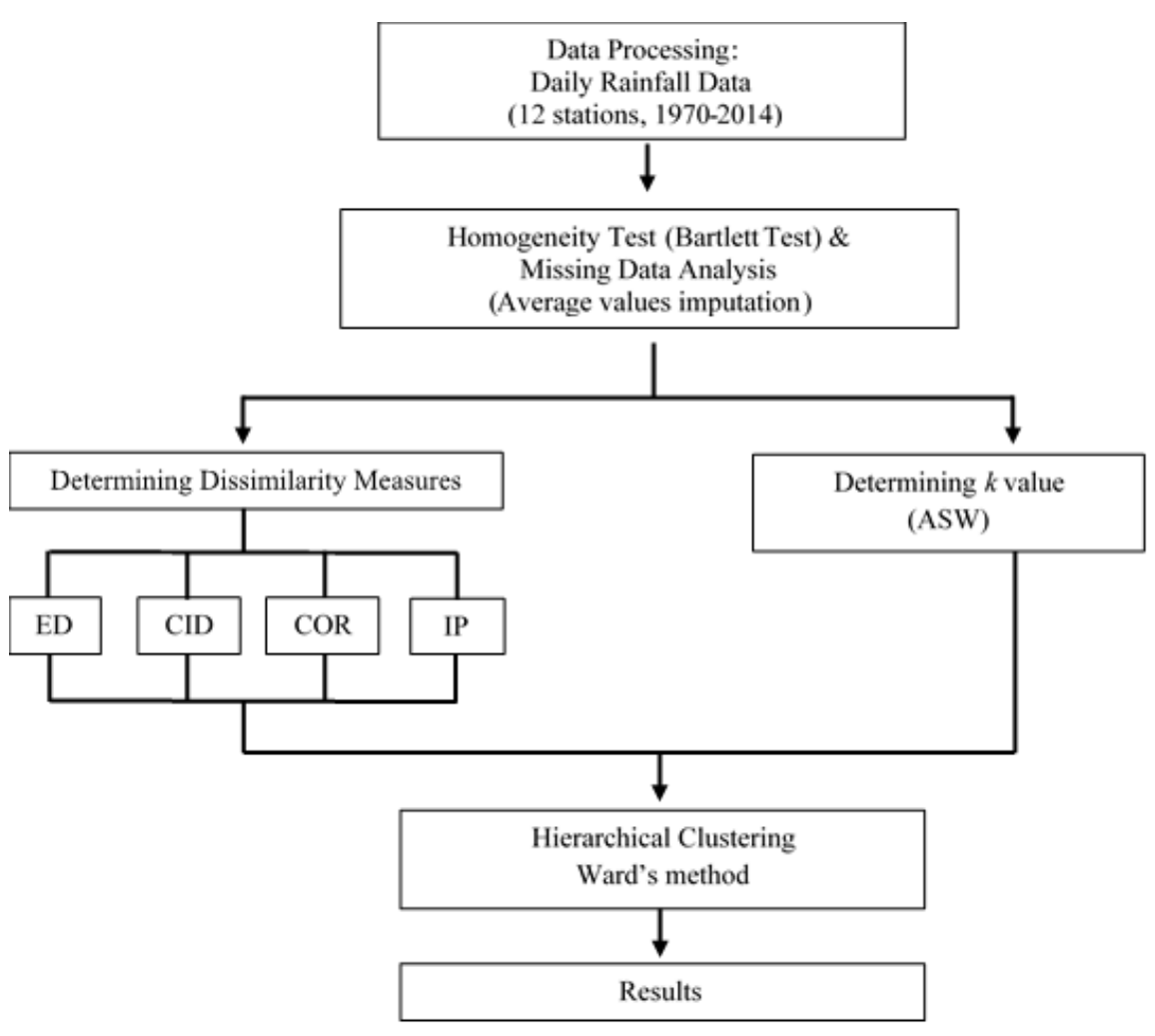

Figure 2: Methodology flowchart. 
THE INTERNATIONAL SEMINAR ON MATHEMATICS IN INDUSTRY (ISMI) AND THE INTERNATIONAL CONFERENCE ON THEORETICAL AND APPLIED STATISTICS (ICTAS) ISMI-ICTAS18 [4-6 SEPTEMBER 2018]

Table 2: Bartlett's test results of the yearly rainfall time series (1970-2014) according to each zone.

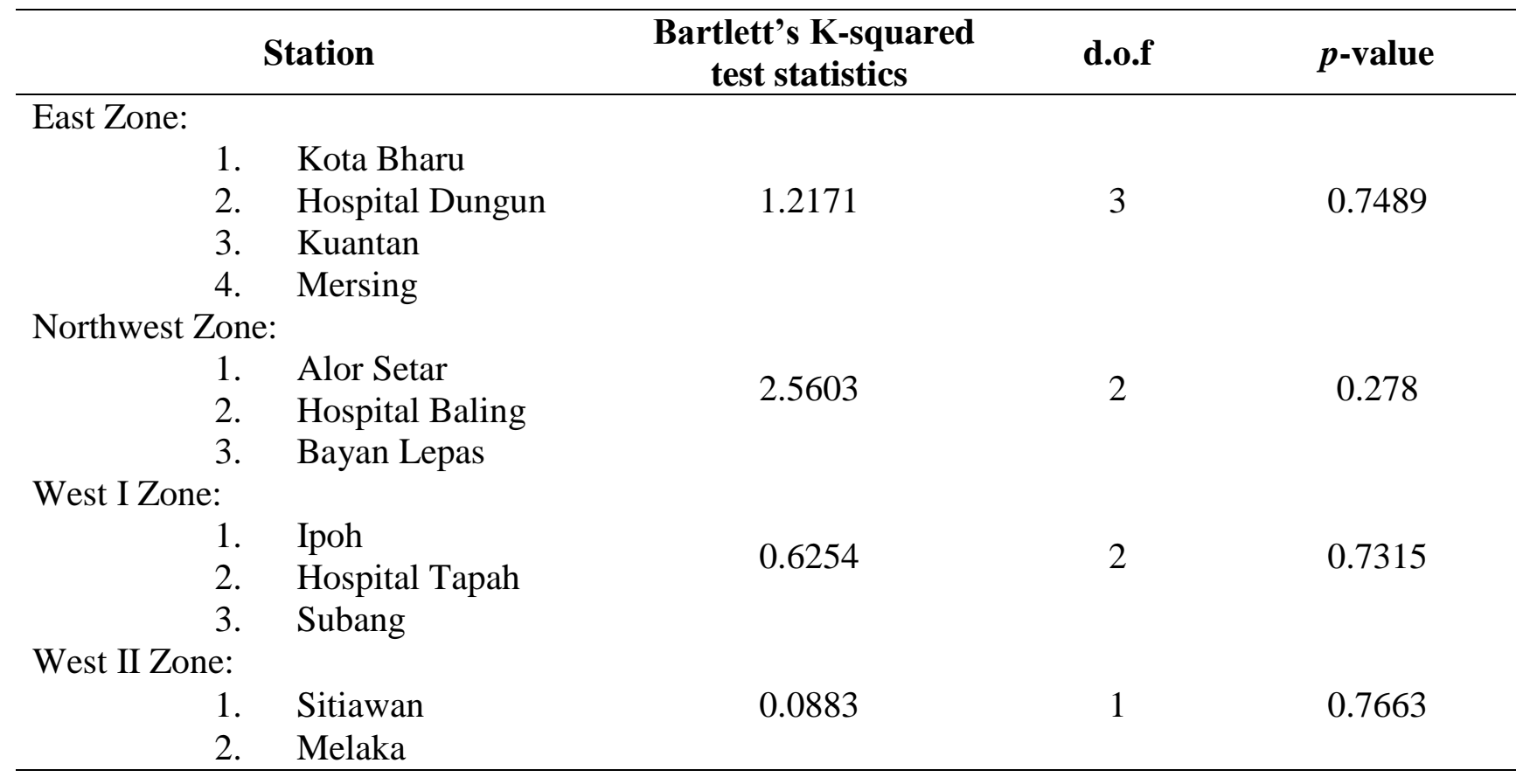

\section{ANALYSIS AND RESULTS}

Figure 2 summarise the flow of analysis process in this study. After rainfall data was processed, Bartlett's test was used to check the homogeneity of variance of the time series data. This is to ensure that the data is of high quality to make sure the results are highly reliable. According to Table 2, the $p$ value for all the tests is not significant. Thus, this no evidence of unequal homogeneity variance within the stations in each cluster. This may imply that the time series data in each clusters have no inhomogeneity issue.

The results for each dissimilarity measure used in clusterisation using Ward's method were compared where the value closer to one is regarded as the most suitable dissimilarity measure for the time series data. At each station, there are three sets of time series data, representing the overall time series data and time series for both monsoon seasons. Using the ASW value, the optimal number of clusters is $k=4$ (Figure 3 ).

The dissimilarity measure results are summarised in Table 3, in which IP is the best dissimilarity measure for cluster analysis of the entire and NEM time series data. The values obtained are closer to one, showing that the real data cluster partitioning is reflected from the model. CID is also suitable for NEM time series while for SWM, COR is the best dissimilarity measure. The simplest dissimilarity measure, ED, does not provide better results for any time series. 
THE INTERNATIONAL SEMINAR ON MATHEMATICS IN INDUSTRY (ISMI) AND THE INTERNATIONAL CONFERENCE ON THEORETICAL AND APPLIED STATISTICS (ICTAS) ISMI-ICTAS18 [4-6 SEPTEMBER 2018]

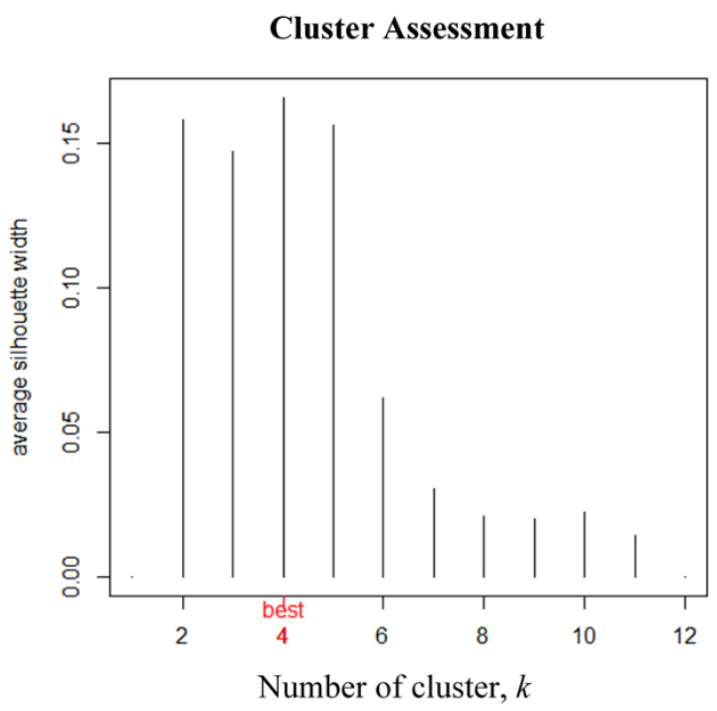

Figure 3: Optimal number of clusters from the ASW method.

Figure 4 shows the hierarchical clustering in the form of dendrograms of the overall time series using all dissimilarity measures. The $y$-axis refers to the difference or dissimilarity between each cluster where the longer the vertical line, the larger the difference between clusters. From this, it is shown that cluster analysis results using IP and COR dissimilarity measures are almost similar. The percentage of stations of each cluster for all types of dissimilarity measures are tabulated in Table 4. Geographical factor and the station locations play a role in determining the clusters, as shown by the clusterisation map in Figure 5, which is based on the IP clusterisation

Table 3: Dissimilarity measure results of overall, Northeast Monsoon (NEM) and Southwest Monsoon (SWM) rainfall time series data.

\begin{tabular}{cccc}
\hline Dissimilarity Measure & & Time Series & \\
Distance & Overall & NEM & SWM \\
\hline ED & 0.4977 & 0.4977 & 0.5583 \\
CID & 0.5857 & 0.6167 & 0.425 \\
IP & 0.7292 & 0.6167 & 0.6167 \\
COR & 0.6792 & 0.5778 & 0.6786 \\
\hline
\end{tabular}


THE INTERNATIONAL SEMINAR ON MATHEMATICS IN INDUSTRY (ISMI) AND THE INTERNATIONAL CONFERENCE ON THEORETICAL AND APPLIED STATISTICS (ICTAS) ISMI-ICTAS18 [4-6 SEPTEMBER 2018]

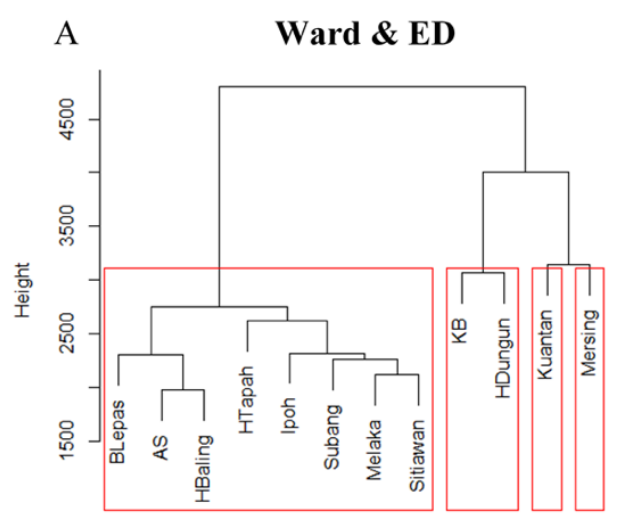

Station

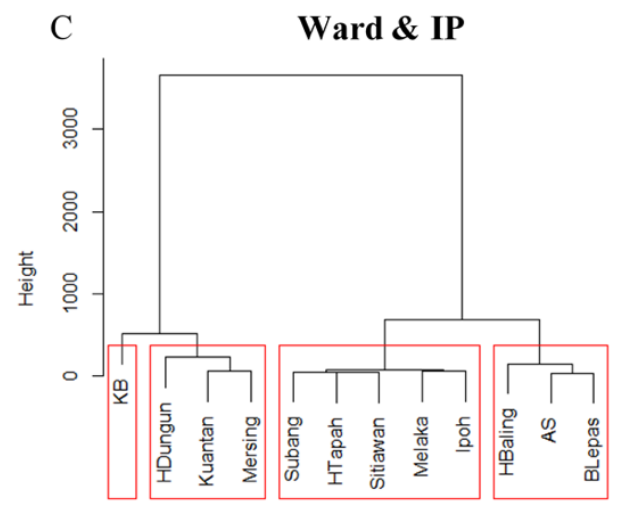

Station

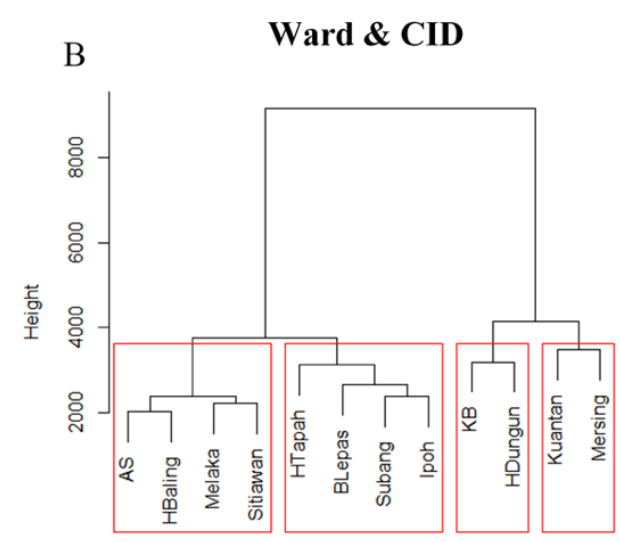

Station

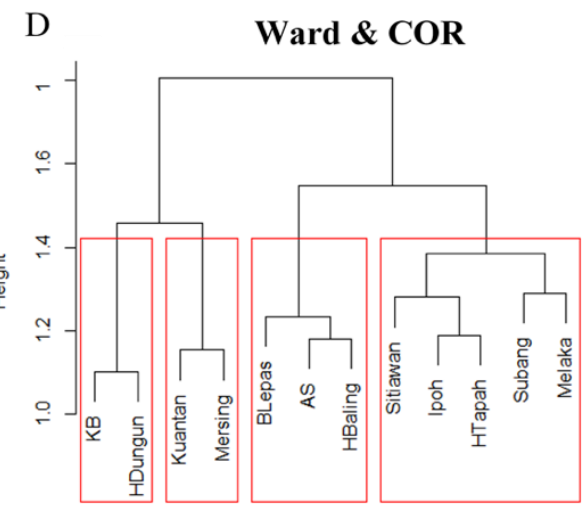

Station

Figure 4: Dendrograms of time series data in 12 stations with dissimilarity measures: ED (A), CID (B), IP (C) and COR (D).

Table 4: The percentage number of stations for each cluster with different dissimilarity measures.

\begin{tabular}{ccccc}
\hline \multirow{2}{*}{ Cluster } & ED & \multicolumn{3}{c}{ Dissimilarity Measures } \\
& CID & IP & COR \\
\hline$\# 1$ & $66.70 \%$ & $33.30 \%$ & $41.70 \%$ & $41.70 \%$ \\
$\# 2$ & $16.70 \%$ & $33.30 \%$ & $25.00 \%$ & $25.00 \%$ \\
$\# 3$ & $8.30 \%$ & $16.70 \%$ & $25.00 \%$ & $16.70 \%$ \\
$\# 4$ & $8.30 \%$ & $16.70 \%$ & $8.30 \%$ & $16.70 \%$ \\
\hline
\end{tabular}


THE INTERNATIONAL SEMINAR ON MATHEMATICS IN INDUSTRY (ISMI) AND THE INTERNATIONAL CONFERENCE ON THEORETICAL AND APPLIED STATISTICS (ICTAS) ISMI-ICTAS18 [4-6 SEPTEMBER 2018]

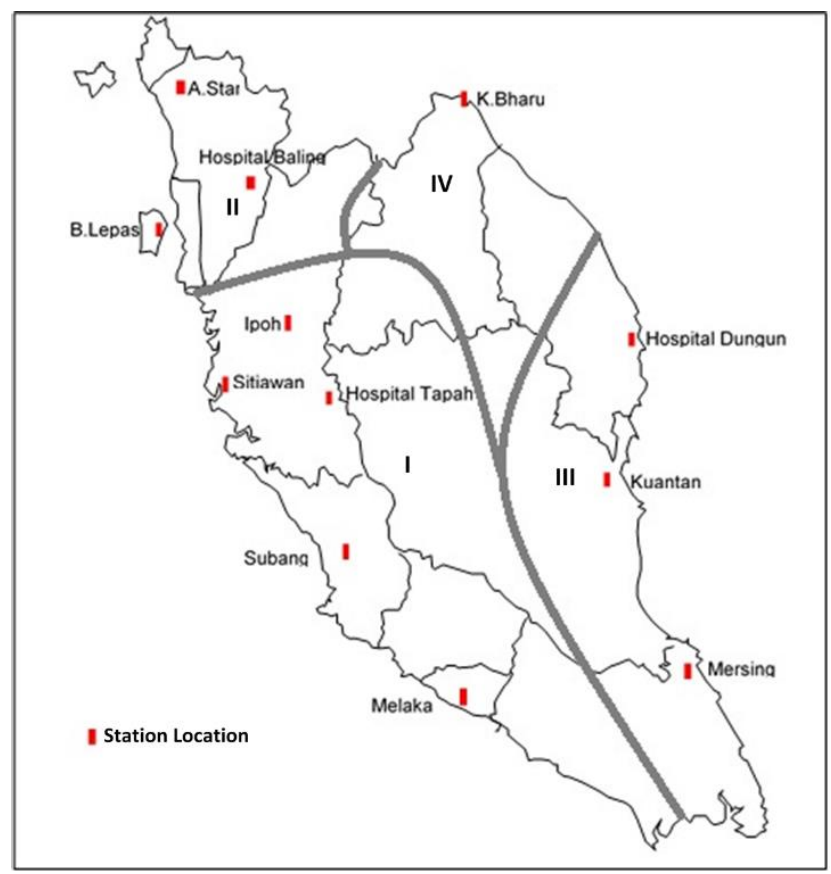

Figure 5: Clusterisation map of the Peninsular Malaysia rainfall data using IP dissimilarity measure based on the overall data.

Figure 6 shows the cluster analysis dendrograms of NEM time series data where CID and IP distance measures produce similar results. During NEM, the east coast area of Peninsular Malaysia receives a lot of rain, thus influencing the cluster analysis results. The percentage number of stations of each cluster for NEM time series data is illustrated in Table 5 and the clusterisation map is depicted in Figure 7.
The cluster analysis dendrograms of SWM time series data is shown in Figure 8, which is different than the NEM time series data. For SWM, the occurrence of rain is lower than the NEM, this significantly influences the determination of clusters than the NEM time series data clusters. For the SWM time series data, the percentage number of stations of each cluster is illustrated in Table 6 and the clusterisation map is depicted in Figure 9. 
THE INTERNATIONAL SEMINAR ON MATHEMATICS IN INDUSTRY (ISMI) AND THE INTERNATIONAL CONFERENCE ON THEORETICAL AND APPLIED STATISTICS (ICTAS) ISMI-ICTAS18 [4-6 SEPTEMBER 2018]
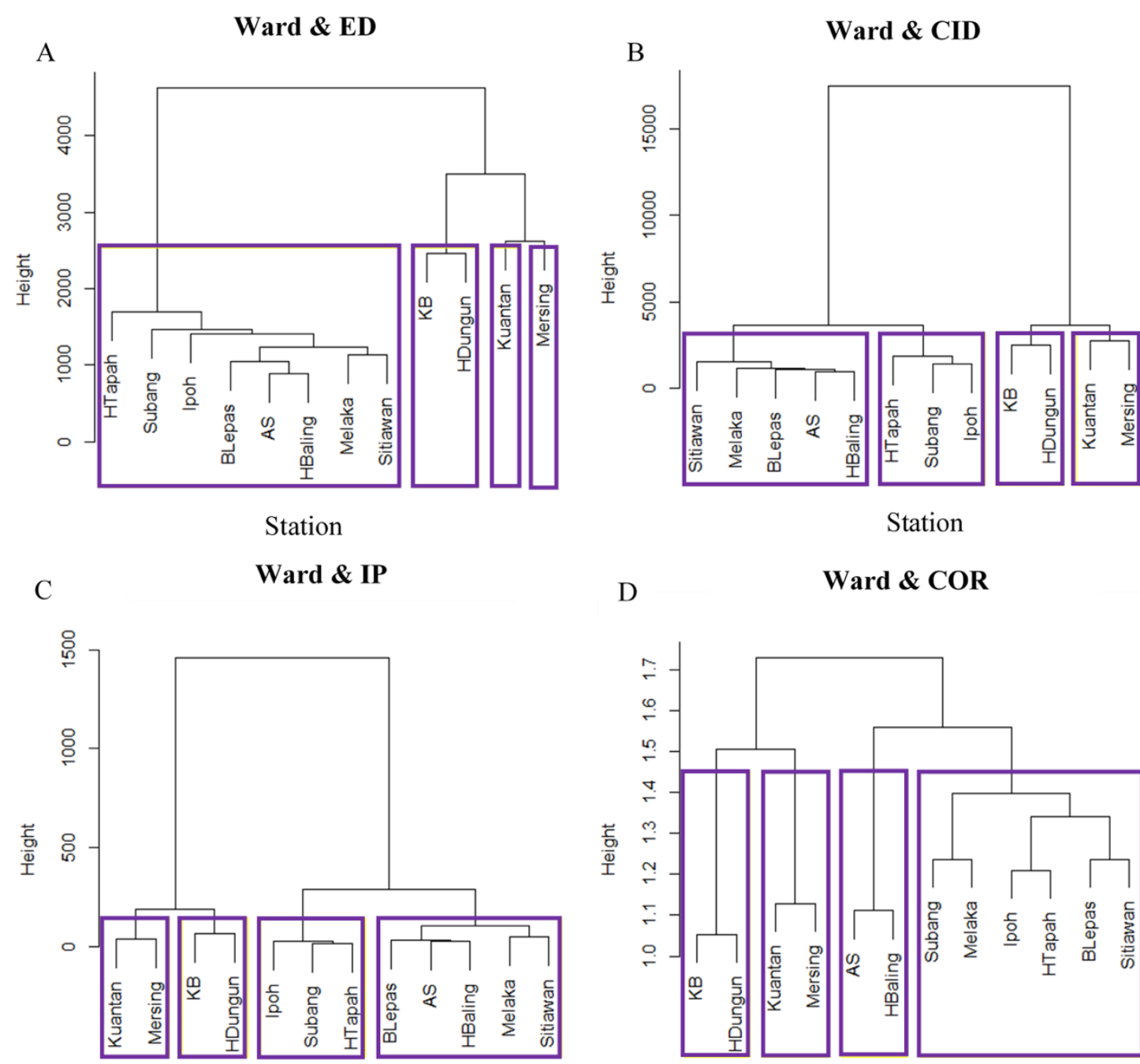

Station

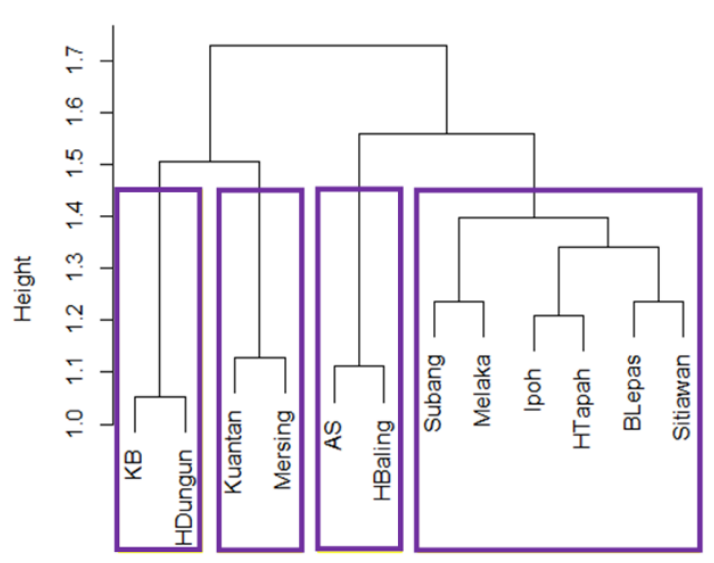

Station

Figure 6: Dendrograms of the Northeast Monsoon (NEM) time series data in 12 stations with dissimilarity measures; ED (A), CID (B), IP (C) and COR (D).

Table 5: The percentage number of stations for each cluster with different dissimilarity measures for the NEM data.

\begin{tabular}{ccccc}
\hline Cluster & ED & Dissimilarity & Measure Distance \\
& $66.70 \%$ & $41.70 \%$ & IP & COR \\
\hline$\# 1$ & $16.70 \%$ & $25.00 \%$ & $25.70 \%$ & $50.00 \%$ \\
$\# 2$ & $8.30 \%$ & $16.70 \%$ & $16.70 \%$ & $16.70 \%$ \\
$\# 3$ & $8.30 \%$ & $16.70 \%$ & $16.70 \%$ & $16.70 \%$ \\
$\# 4$ & & & $16.70 \%$ \\
\hline
\end{tabular}


THE INTERNATIONAL SEMINAR ON MATHEMATICS IN INDUSTRY (ISMI) AND THE INTERNATIONAL CONFERENCE ON THEORETICAL AND APPLIED STATISTICS (ICTAS) ISMI-ICTAS18 [4-6 SEPTEMBER 2018]

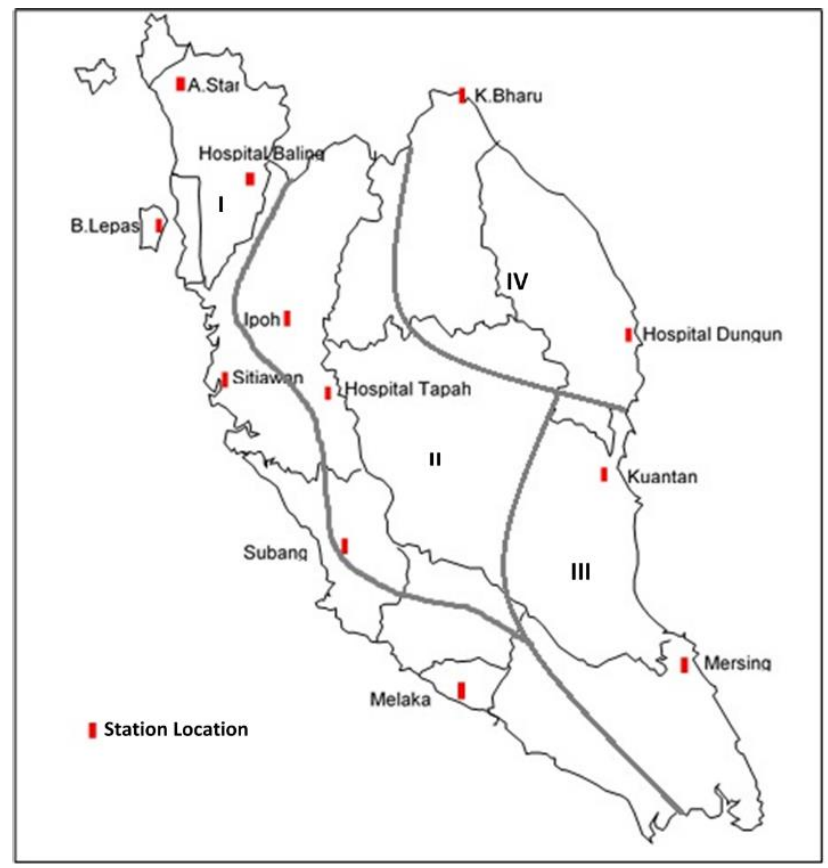

Figure 7: Clusterisation map of the Peninsular Malaysia rainfall data using CID or IP dissimilarity measure based on the NEM data. 
THE INTERNATIONAL SEMINAR ON MATHEMATICS IN INDUSTRY (ISMI) AND THE INTERNATIONAL CONFERENCE ON THEORETICAL AND APPLIED STATISTICS (ICTAS) ISMI-ICTAS18 [4-6 SEPTEMBER 2018]

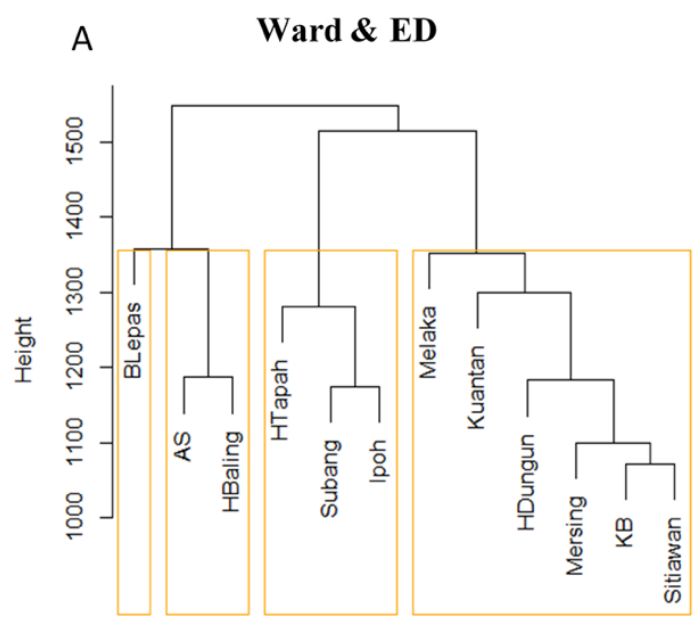

Station

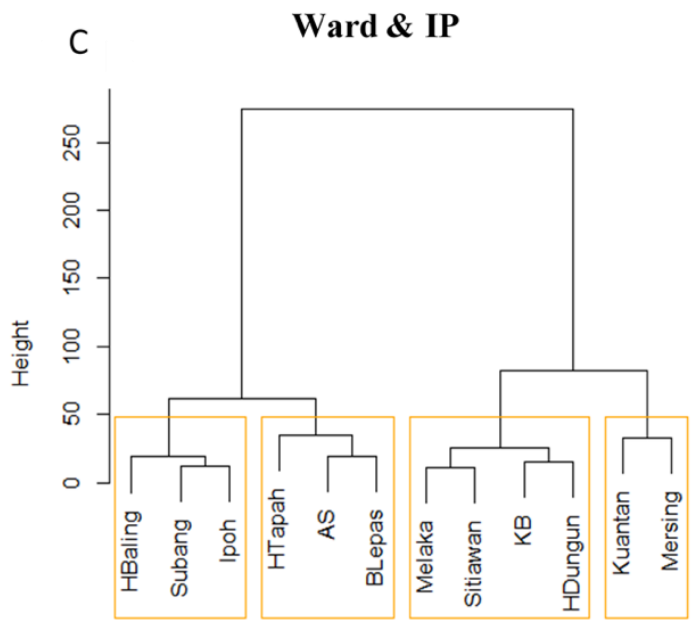

Station

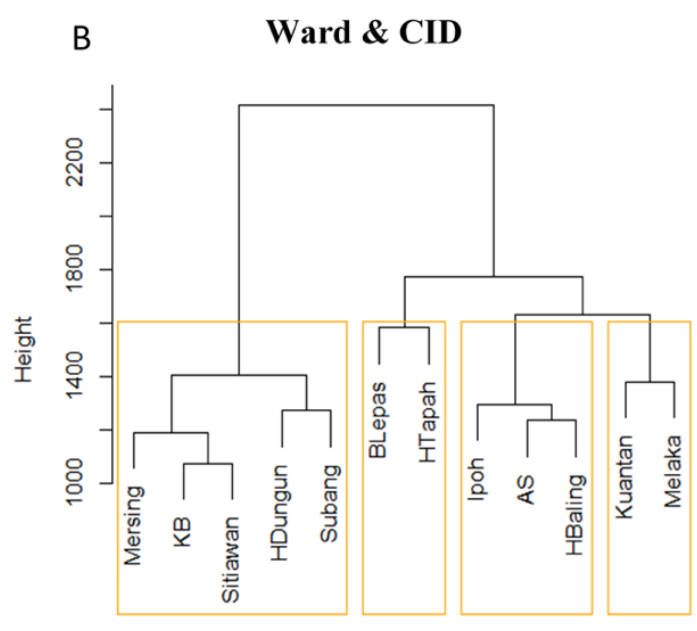

Station

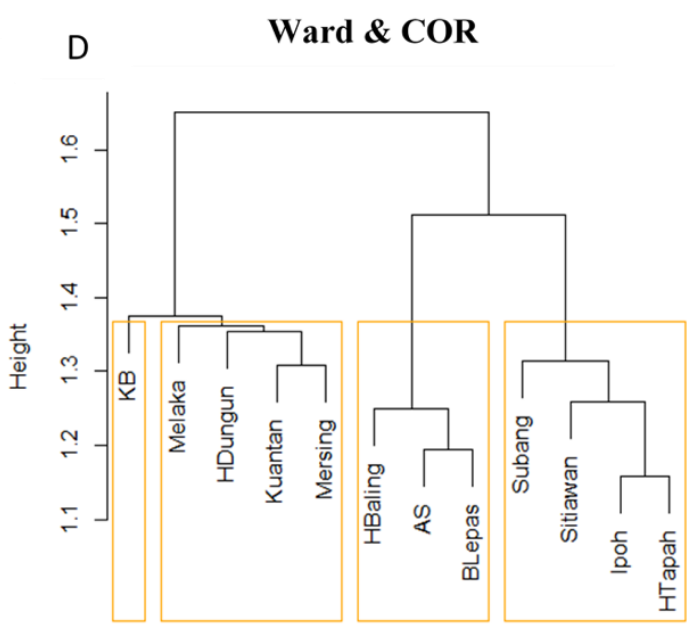

Station

Figure 8: Dendrograms of the Southwest Monsoon (SWM) time series data in 12 stations with dissimilarity measures; ED (A), CID (B), IP (C) and COR (D).

Table 6: The percentage number of stations of each cluster with different dissimilarity measures for the SWM data.

\begin{tabular}{ccccc}
\hline Cluster & ED & \multicolumn{3}{c}{ Dissimilarity Measure Distances } \\
& CID & IP & COR \\
\hline 1 & $50.00 \%$ & $41.70 \%$ & $33.30 \%$ & $33.30 \%$ \\
$\# 2$ & $25.00 \%$ & $25.00 \%$ & $25.00 \%$ & $33.30 \%$ \\
$\# 3$ & $16.70 \%$ & $16.70 \%$ & $25.00 \%$ & $25.00 \%$ \\
$\# 4$ & $8.30 \%$ & $16.70 \%$ & $16.70 \%$ & $8.30 \%$ \\
\hline
\end{tabular}


THE INTERNATIONAL SEMINAR ON MATHEMATICS IN INDUSTRY (ISMI) AND THE INTERNATIONAL CONFERENCE ON THEORETICAL AND APPLIED STATISTICS (ICTAS) ISMI-ICTAS18 [4-6 SEPTEMBER 2018]

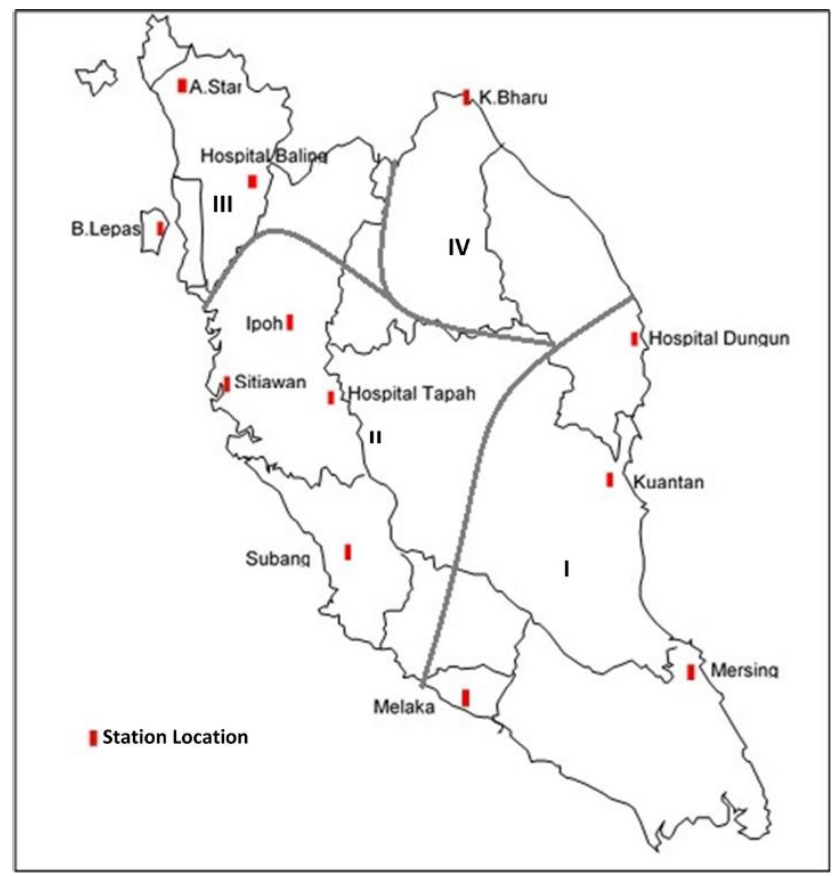

Figure 9: Clusterisation map of the Peninsular Malaysia rainfall data using COR dissimilarity measure based on the SWM data.

\section{CONCLUSION}

This study shows that the time series clusterisation can be used to study the rainfall pattern in Malaysia. Given that the Malaysian climate has two monsoon seasons, the cluster analysis should be done separately. For Peninsular Malaysia, the optimal cluster number is four, in which Peninsular Malaysia is divided into four homogeneous climate zones, especially the northwest and east coast regions. Factors such as geographical region, locations and precipitation rate play a role in determining the clusters. IP dissimilarity measure is the most suitable measure for the analysis on the overall time series data, while IP and CID are for the NEM data and COR is for the SWM. From the results, it is concluded that Ward's method is useful to cluster the Malaysian rainfall time series data. This approach can be extended by using other clustering techniques such as wavelet clustering (Singhal \& Seborg, 2005) and can be used for storm event clustering (Ariff et al., 2016).

\section{ACKNOWLEDGEMENT}

The authors would like to thank Universiti Kebangsaan Malaysia for allocating the research grants (GGPM-2015-026 and GGPM-2017-124) and its facilities for this research.

\section{REFERENCES}

Aghabozorgi, S., Shirkhorshidi, A.S. \& Wah, T.Y. (2015). Time-series clustering-A decade review. Information Systems, 53: $16-38$.

Ahmad N.H., Othman I.R. \& Deni S.M. (2013). Hierarchical cluster approach for regionalization of Peninsular Malaysia based on the precipitation amount. Journal of Physics: Conference Series, 423(1): 12-18.

Ariff N.M., Bakar M.A.A. \& Rahmad M.I. (2018). Comparative study of 
THE INTERNATIONAL SEMINAR ON MATHEMATICS IN INDUSTRY (ISMI) AND THE INTERNATIONAL CONFERENCE ON THEORETICAL AND APPLIED STATISTICS (ICTAS) ISMI-ICTAS18 [4-6 SEPTEMBER 2018]

document clustering algorithms. International Journal of Engineering and Technology (UAE), 7(4): 246251.

Ariff N.M., Jemain A.A. \& Bakar M.A.A. (2016). Regionalization of IDF curves with L-moments for storm events. International Journal of Mathematical and Computational Sciences, 10: 217223.

Arifin A.Z. \& Asano A. (2006). Image segmentation by histogram thresholding using hierarchical cluster analysis. Pattern Recognition Letters, 27(13): 1515-1521.

Batista G.E., Keogh E.J., Tataw O.M. \& De Souza V.M. (2014). CID: an efficient complexity-invariant distance for time series. Data Mining and Knowledge Discovery, 28(3): 634-669.

Crétat J., Richard Y., Pohl B., Rouault M., Reason C. \& Fauchereau N. (2012). Recurrent daily rainfall patterns over South Africa and associated dynamics during the core of the austral summer. International Journal of Climatology, 32(2): 261-273.

De Lucas D.C. (2010). Classification Techniques for Time Series and Functional Data. Universidad Carlos III de Madrid. Doctoral dissertation.

DeGaetano A.T. (2001). Spatial grouping of United States climate stations using a hybrid clustering approach. International Journal of Climatology, 21(7): 791-807.

Han J., Pei J. \& Kamber M. (2012). Data Mining: Concepts and Techniques 3rd Edition. Waltham, M.A.: Morgan Kaufmann Publishers.
Kavitha V. \& Punithavalli M. (2010). Clustering time series data stream-a literature survey. International Journal of Computer Science and Information Security, 8(1):289-294.

Lin J. \& Li Y. (2009). Finding Structural Similarity in Time Series Data Using Bag-of-Patterns Representation. In Proceedings of the 21st International Conference on Scientific and Statistical Database Management, 461-477.

Michinaka T., Tachibana S. \& Turner J.A. (2011). Estimating price and income elasticities of demand for forest products: cluster analysis used as a tool in grouping. Forest Policy and Economics, 13(6): 435-445.

Munoz-Diaz D. \& Rodrigo F.S. (2004). Spatio-temporal patterns of seasonal rainfall in Spain (1912-2000) using cluster and principal component analysis: comparison. Annales Geophysicae, 22(5): 1435-1448.

Prasanna K.A.V.L. (2012). Performance evaluation of multiviewpoint-based similarity measure for data clustering. Journal of Global Research in Computer Science, 3(11): 21-26.

Ramos M.C. (2001). Divisive and hierarchical clustering techniques to analyse variability of rainfall distribution patterns in a Mediterranean region. Atmospheric Research, 57(2):123-138.

Maharaj E.A., D'Urso P. \& Galagedera D.U. (2010). Wavelet-based fuzzy clustering of time series. Journal of Classification, 27(2): 231-275. 
THE INTERNATIONAL SEMINAR ON MATHEMATICS IN INDUSTRY (ISMI) AND THE INTERNATIONAL CONFERENCE ON THEORETICAL AND APPLIED STATISTICS (ICTAS) ISMI-ICTAS18 [4-6 SEPTEMBER 2018]

Rani, S. \& Sikka, G. (2012). Recent techniques of clustering of time series data: a survey. International Journal of Computer Applications, 52(15): 19.

Soltani S. \& Modarres R. (2006). Classification of spatio-temporal pattern of rainfall in Iran using a hierarchical and divisive cluster analysis. Journal of Spatial Hydrology, 6(2): 1-12.
Tennant W.J. \& Hewitson B.C. (2002). Intraseasonal rainfall characteristics and their importance to the seasonal prediction problem. International Journal of Climatology: A Journal of the Royal Meteorological Society, 22(9): 1033-1048. 